\title{
Fetal adrenal Biometry, Cervical Assessment and Inflammatory Cytokine for Prediction of Preterm Labor: Comparative Study \\ Rasha R. Abd Elhady ${ }^{1}$, Alia A. El Shahaway ${ }^{2}$, Basem Hamed ${ }^{1}$ \\ ${ }^{1}$ Department of Obstetrics and Gynecology, ${ }^{2}$ Department of Medical Microbiology and Immunology, Faculty of Medicine, Zagazig University, Egypt \\ Corresponding Author: Rasha R. Abd Elhady, mobile:00201011252854, Email address: rashareda@gmail.com
}

\begin{abstract}
Background: Preterm birth is a multifactorial problem with a confounding management. Latent interval (Time to delivery) always shows wide variation and presence of a valid, reliable and applicable predictor is a controversial issue. Objectives: to evaluate the role of fetal adrenal biometry (corrected-total gland volume c-TGV and fetal zone enlargement FZE), cervical length and IL17 serum level (maternal inflammatory biomarker) in prediction of preterm that could help in proper management and decreased morbidities.

Patient and Methods: Observational comparative study for 100 case (28 to 36 weeks gestation) showing clinical signs of threatened preterm labor. Corrected fetal adrenal gland volume, fetal zone enlargement, cervical length and IL17 serum level were measured then all candidates were followed up till delivery to classify the results into two groups according to the (latent interval). Diagnostic performance for all variables was done to detect the best cutoff value that can predict impending preterm delivery within 7 days using univariate analysis and receiver operating characteristic (ROC) curve.

Results: The studied predictors were showing best cutoff, sensitivity\%, specificity\% and accuracy\% as follow: c-TGV $\left(\geq 400 \mathrm{~mm}^{3} / \mathrm{kg}, 80,75,85\right), \mathrm{FZE}(\geq 50 \%, 90,80,92)$, cervical length ( $\left.\leq 16 \mathrm{~mm}, 70,67,65\right)$, IL17 serum level (8 pg/ml, $80,95,83)$ respectively.

Conclusion Utility of corrected fetal adrenal gland volume, fetal zone enlargement in addition to the IL17 (inflammatory marker) as a non-invasive predictors for impending preterm birth can guide a proper decision.

Keywords: Cervix, Fetal adrenal, Inflammatory biomarker, Preterm labor
\end{abstract}

\section{INTRODUCTION}

Preterm labor is the start of delivery before 37 weeks gestation and beyond the age of viability, unfortunately it is a worldwide problem and represents a socioeconomic burden especially in the developing countries ${ }^{(1)}$.

Prediction of preterm birth has a great importance to reduce the neonate's morbidity and mortality, as many clinical, biochemical and sonographic methods are tested to get the best tool with the highest accuracy, they include modified Bishop score, fetal fibronectin test, maternal cortisol levels and plasma level of corticotrophin-releasing hormone (CRH), but with controversial results owing to their variable accuracy, practical implementation, cost benefit relation and subjective operator dependence ${ }^{(2)}$.

Sonographic cervical length is considered as an essential part of the routine obstetric ultrasound assessment ${ }^{(3)}$. Short cervix is defined as $<25 \mathrm{~mm}$ or $<10^{\text {th }}$ centile at (24-28) weeks gestation ${ }^{(4)}$.

Parturition is a complex process that based on the integration of multiple maternal and fetal factors initially controlled by fetal hypothalamic-pituitaryadrenal (HPA) axis ${ }^{(5)}$. Fetal cortisol theory (as called previously) states that adrenal gland plays a vital role by secretion of dehydroepiandrosterone- sulfate (DHEA-S), which in turn up regulates the placental CRH with further secretion of prostaglandins PGE2 and PGF2a leading to the onset of contraction ${ }^{(6)}$. So, premature release of placental CRH is considered as a biological alarm in the early onset delivery ${ }^{(7,8)}$. Thus, the release of fetal adrenal steroid precursors could be associated with enlargement of the central zone of the gland ${ }^{(9)}$.

Preterm labor is commonly associated with uterine subclinical infection and inflammatory response causes contraction and delivery. Therefore, the release of pro-inflammatory cytokines such as TNFa, IL-1, IL6 and IL-8 is expected to increase in amniotic fluid, decidual and chorionic tissue. IL-17 is important to host immune response and is considered a key cytokine that induces inflammation also might have some roles in pathophysiology of preterm birth ${ }^{(\mathbf{1 0})}$.

Recent possible suggestion supposes that preterm birth specially associated with chorioamnionitis is accompanied by Th-17 activation with further production a pro-inflammatory cytokine IL-17 that causes the liberation of prostaglandin E2 resulting in uterine contraction and preterm labor ${ }^{(11,12)}$.

The final result of all possible mechanisms is cervical remodeling, softening, ripening and progressive dilatation ${ }^{(13)}$. So, in the current study we tried to evaluate the validity of the previously mentioned factors that could help in preterm birth prediction. 


\section{PATIENT AND METHODS}

Observational comparative study was done at "antenatal outpatient clinics of Obstetrics and Gynecology Department", Hospitals of Zagazig University. Sample size was One hundred patients calculated through open-Epi (CI 95\% and power 82\%), selected according to the following eligibility criteria:

Diagnosis of threatened preterm labor (PTL) based on: gestational age (GA) (28-36 week) with regular contractions (>4 in 20 minutes) and each one lasts $>40 \mathrm{sec}$ with progressive cervical dilatation $>1 \mathrm{~cm}$ and $<3 \mathrm{~cm}^{(14)}$ and $(+/-)$ premature rupture of membranes (PROM). Excluding cases with medical disorders, maternal or fetal infection (fever $>38.0^{\circ} \mathrm{C}$, tenderness, fetal tachycardia or even abnormal fetal heart rate (FHR)) and congenital anomalies.

All women were submitted to the following: clinical history, general examination and routine obstetric ultrasound using 2D voluson p8 ultrasound (General Electric, Egypt) with (3-5 MHz) convex transducer to check the fulfillment of the inclusion criteria.

Fetal adrenal Biometry: In the lower axial plane at the kidney level, simple sliding up for the transducer to get the fetal adrenal gland, which is characterized by outer hypoechoic cortex and hyper echogenic stroma (fetal zone). The left gland was selected due to its semilunar shape, then the total gland and the fetal zone dimensions were measured as follow: length (L) in the axial plane and width (W) and depth (D) were taken in the coronal plane. (90 degree transducer rotation could help and in case of untoward fetal position 3Dmultiplanar plane was considered).

Fetal zone depth (d)/total gland depth (D) ratio was calculated as an indicator for the adrenal fetal zone enlargement (FZE) ${ }^{(15)}$. The total volume of the gland was calculated using the ellipsoid formula $(\mathrm{L} * \mathrm{~W} * \mathrm{D} * 0.52)$ and subdivided by the expected fetal weight to get (c-TGV) presented as $\left(\mathrm{mm}^{3} / \mathrm{kg}\right)$ to nullify GA effect. Expected fetal weight was calculated using famous Hadlock formula based on four famous fetal biometric parameters (biparietal diameter, head circumference, abdominal circumference and femur length) $)^{(15)}$.

Residual cervical length was assessed transvaginal in the sagittal plane in cases with intact membranes or translabial in case of preterm premature rupture of membranes (PPROM) with avoidance of probe compression.
IL-17A Serum level was assessed through collection of $5 \mathrm{ml}$ blood sample at the time of admission from all candidates under complete aseptic conditions. Serum samples were separated and frozen at $-20^{\circ} \mathrm{C}$ to protect the human bioactive IL-17A which was calculated by IL-17 Sandwich ELISA Kit following the manufacturer's instructions (Thermo Fisher Scientific Inc., USA, BMS2017). Mean absorbance was assessed at $450 \mathrm{~nm}$ wavelength and concentration of IL-17 presented as (pg/ml) with sensitivity limit $0.5 \mathrm{pg} / \mathrm{ml}$.

\section{Ethical approval:}

The study conducted according to the Declaration of Helsinki and has approved from the institutional review board Faculty of Medicine, Zagazig University. Informed consent was obtained from all patients.

\section{Statistical analysis}

Was performed using (SPSS, Inc., Chicago, IL) program version 14. Data were displayed as mean $\pm(\mathrm{SD})$ or percentage according to its type (quantitative, qualitative) respectively. Comparing means was done by univariate study using independent t- test, comparing medians by pearson's chi-square test and for data not normally distribute Mann-Whitney test was used. Receiver operating characteristic (ROC) curve with confidence interval (CI) $95 \%$ was used to detect the best cutoff values for the studied variables. Sensitivity, specificity, accuracy were used to test the validity of different variables. P-value was considered significant if $<0.05$.

\section{RESULTS}

One hundred threatened preterm patient were enrolled in the study. Unfortunately, data of five patients were missed so the final study population became 95 candidates. Clinical, sonographic and biochemical variables were recorded then followed up till the delivery.

The clinical outcome was classified into two groups according to the latent period: group $A$ (latent period $\leq 7$ days) $\mathrm{No}=34(36 \%)$ and group $B$ (latent period $>7$ days) $\mathrm{No}=61(64 \%)$. Clinical parameters included Maternal age \& gestational age at admission was showing significant values but not the parity. (Table1) Cervical length (Table2) also was showing non-significant difference between both groups.

Table (1): Univariate analysis comparing demographic variables between both groups

\begin{tabular}{|l|c|c|c|c|}
\hline \multicolumn{2}{|c|}{ Demographic variables } & Group A (n=34) & Group B (n=61) & P value \\
\hline Maternal age (year) & Mean \pm SD & $26.2 \pm 4.8$ & $23.6 \pm 5.2$ & 0.02 \\
\hline $\begin{array}{l}\text { Gestational age (week) At time of } \\
\text { admission }\end{array}$ & Mean \pm SD & $34 \pm 1.7$ & $33 \pm 2.6$ & $<0.05$ \\
\hline Parity (0-4) & Median (range) & $0(0-3)$ & $1(0-4)$ & 0.5 \\
\hline
\end{tabular}

Gestational age at time of delivery was classified to 3 categories with highly significant difference between both groups for age category $(\leq 34$ weeks) \& $(21 \%)$ only of group B continue till term. other predictors (c-TGV, FZE and IL17) were showing significant difference with variable degrees (Table2). 
Table (2): Univariate analysis comparing the studied predictors between both groups

\begin{tabular}{|c|c|c|c|c|c|}
\hline \multicolumn{3}{|c|}{ Parameter } & $\begin{array}{c}\text { Group A } \\
(\mathbf{n}=34)\end{array}$ & $\begin{array}{l}\text { Group B }(n= \\
61)\end{array}$ & $P$ value \\
\hline \multicolumn{3}{|c|}{$\begin{array}{l}\text { Gestational age (weeks) At time of } \\
\text { Delivery }\end{array}$} & & & \\
\hline \multicolumn{2}{|c|}{$\begin{array}{l}\leq 34 \text { weeks } \\
>34-37 \text { weeks } \\
>37 \text { weeks }(\text { term) }\end{array}$} & $\begin{array}{l}\mathrm{n}(\%) \\
\mathrm{n}(\%) \\
\mathrm{n}(\%)\end{array}$ & $\begin{array}{c}20(58 \%) \\
14(42 \%) \\
--(0 \%)\end{array}$ & $\begin{array}{c}17(28 \%) \\
31(50.8 \%) \\
13(21 \%)\end{array}$ & $\begin{array}{l}0.003 \\
0.37 \\
0.03\end{array}$ \\
\hline \multicolumn{3}{|c|}{$\begin{array}{l}\text { Cervical Length }(\mathrm{mm}) \\
\pm \mathrm{SD})\end{array}$} & $18 \pm 3$ & $22 \pm 6$ & 0.06 \\
\hline \multirow{2}{*}{$\begin{array}{l}\text { Fetal } \\
\text { Adrenal } \\
\text { biometry } \\
\text { (Mean } \\
\pm \mathrm{SD}) \\
\end{array}$} & \multicolumn{2}{|c|}{$\begin{array}{l}\text { Corrected- total gland } \\
\text { volume } \\
(\mathrm{c}-\mathrm{TGV})\left(\mathrm{mm}^{3 / \mathrm{kg}}\right)\end{array}$} & $550 \pm 200$ & $315 \pm 110$ & 0.001 \\
\hline & \multicolumn{2}{|c|}{$\begin{array}{l}\text { Fetal zone enlargement } \\
(\mathrm{FZE})(\%)\end{array}$} & $60 \pm 3.2$ & $40 \pm 3.1$ & 0.001 \\
\hline \multicolumn{3}{|c|}{ IL17 (pg/ml) } & $9.2 \pm 5$ & $4.4 \pm 3.6$ & 0.0001 \\
\hline
\end{tabular}

By testing the diagnostic performance (by ROC curve) for the studied variables in predicting preterm birth, we found the best cutoff for each one as follow: Gestational age (At time of Delivery) ( $\leq 34 \mathrm{wk}$ ), c-TGV ( $\geq 400 \mathrm{~mm}^{3} / \mathrm{kg}$ ), FZE ( $\geq$ $50 \%)$, CL $(\leq 16 \mathrm{~mm})$ and IL17 serum level $(\geq 8 \mathrm{pg} / \mathrm{ml})$ with marked sensitivity, specificity and accuracy as described below (Table 3)

Table (3): Diagnostic performance of each studied predictor associated with preterm birth

\begin{tabular}{|l|c|c|c|c|}
\hline \multicolumn{1}{|c|}{ variables } & Cutoff & Sensitivity & Specificity & Accuracy \\
\hline $\begin{array}{l}\text { GA (At time of } \\
\text { Delivery) }\end{array}$ & $\leq 34$ weeks & 75 & 60 & 72 \\
\hline Cervical Length & $\leq 16 \mathrm{~mm}$ & 70 & 67 & 65 \\
\hline C-TGV & $\geq 400 \mathrm{~mm}^{3 / \mathrm{kg}}$ & 80 & 75 & 85 \\
\hline FZE & $\geq 50 \%$ & 90 & 80 & 92 \\
\hline IL17 & $\geq 8 \mathrm{pg} / \mathrm{ml}$ & 80 & 95 & 83 \\
\hline
\end{tabular}

\section{DISCUSSION}

Preterm delivery; being managed conservatively, it may consume unnecessary lines of treatment (cerclage, tocolysis and steroid dose) leading to rising of health care cost especially in developing countries. Recently, searching for non-invasive predictors gains a significant attention because up till now clinicians cannot expect the success of the tocolytic drugs, with rising debate concerning fetal adrenal biometry and inflammatory biomarkers ${ }^{(15,18)}$.

In this paper; a group of threatened preterm birth patients (28-36 week) was enrolled to assess the diagnostic performance of different predictors between two groups: group A with imminent delivery, (short latent period) and group B with remote delivery (long latent period).

We revealed the following: There was highly significant difference regarding the studied fetal adrenal biometric variables (c- FGV, FZE); ROC curve recorded a cutoff value $\left(\geq 400 \mathrm{~mm}^{3} / \mathrm{kg}, \geq 50 \%\right)$ with sensitivity and specificity $(80 \%, 75 \%)$ and $(90 \%, 80 \%)$ respectively.

Confirming the current results, Turan et al. stated that preterm fetuses have increase in the adrenal gland volume significantly, they conduct two studies in this issue and record a cutoff value for cAGV $\left(422 \mathrm{~mm}^{3} / \mathrm{kg}\right)$ with $92 \%$ sensitive and $99 \%$ specificity for labor within
5 days in the $1^{\text {st }}$ study (16) and another cutoff value of $420 \mathrm{~mm}^{3} / \mathrm{kg}$ with $81 \%$ sensitivity and $87 \%$ specificity was found in the $2^{\text {nd }}$ one ${ }^{(15)}$. The markers of fetal adrenal gland enlargement (FZE and cAGV) showed higher significant values in the preterm group than the term ${ }^{(15)}$. Agarwal $\boldsymbol{e t}$ al. addressed fetal adrenal gland biometry in prediction of preterm delivery, they stated that FZE of both glands were similar to each other nullifying the conflict about gland selection. Also they recorded similar data to that found in the current study which included c-AGV, which was higher in preterm group with $67 \%$ sensitivity and $76 \%$ specificity at cutoff 415 $\mathrm{mm}^{3} / \mathrm{kg}$, while enlargement of the adrenal fetal zone showed $90 \%$ sensitivity and $80 \%$ specificity at cutoff value of $47.7 \%{ }^{(17)}$.

In the current study, there was no significant difference between both groups regarding the cervical length with recorded best cutoff $(16 \mathrm{~mm})$ and sensitivity (70\%), specificity (67\%) and weak accuracy (65\%). Berghella et al. also stated that a $25 \mathrm{~mm}$ cutoff value should be used only for cases not showing premature contraction ${ }^{(4)}$. Many reports noticed gradual cervical shortening beyond 30 weeks gestation, so it should not be used as a predictor for preterm birth. The conflict could be due to $50 \%$ of cases and cervical length $<25$ $\mathrm{mm}$ may have term delivery ${ }^{(3)}$. Agarwal et al. mentioned a cutoff value $(20 \mathrm{~mm})$ with $63 \%$ sensitivity 
and $47 \%$ specificity for the cervical length as a predictor but despite they conduct a great study, their results in this point are doubted as they used transabdominal prob for evaluation of the cervix ${ }^{(17)}$.

Guler et al. compared the diagnostic accuracies of cervical length and FZE as predictors of PTB and revealed that 29 preterm cases in contrast to 33 cases of spontaneous term delivery FZD/TGD ratio was higher in preterm group $(\mathrm{P}<0.001)$ and non-significant value $(0.27)$ for cervical length then propound that the fetal adrenal gland volume and fetal zone enlargement may add a benefit for the cases presented with preterm labor $^{(5)}$.

Concerning our results, there was a significant difference regarding serum level of IL-17 between both groups and cutoff ( $\geq 8 \mathrm{pg} / \mathrm{ml}$ ) for predicting preterm birth with sensitivity $(80 \%)$ and specificity $(95 \%)$. Elevation of cytokines in the amniotic fluid may be an initial step in the onset of labor as the cytokines play a vital role in the stimulation of prostaglandin release ${ }^{\left({ }^{18)}\right.}$. Ito et al. approved these data in their study, amniocentesis was done to 154 pregnant women with preterm labor at gestational age (22-34) weeks, they found an increase in the levels of IL-17 in the amniotic fluid in the cases with symptoms of preterm labor ${ }^{(\mathbf{1 2})}$. Prospective cohort study conducted by Gargano et al. tested Th1, Th2 and Th17 cytokines (including IL-17) in 926 pregnant women with medically indicated preterm delivery. They reported that serum levels of IL17 in the cases with spontaneous preterm labor at second trimesters increased despite not accompanied by histological chorioamnionitis ${ }^{(\mathbf{1 9})}$.

The cytokines elevation in the amniotic fluid could be a defense mechanism from the macrophage activity keeping the immunosurveillance of the fetus, which in turn could be considered as a valid noninvasive predictor for the start of the preterm birth.

\section{CONCLUSION}

This paper highlights the importance of utility of non-invasive and rapid tools for predictive purpose and clarify the accuracy of fetal adrenal parameters and the serum IL17 value in assessment of the latent period in cases of threatened preterm labor.

\section{No Conflict of interest.}

\section{No Funding.}

\section{REFERENCES}

1. Beck S, Wojdyla D, Say L et al. (2010): The worldwide incidence of preterm birth: A systematic review of maternal mortality and morbidity. Bull World Health Organ, 88: 31-38.

2. Korebrits C, Ramirez M, Watson L et al. (1998): Maternal corticotropin-releasing hormone is increased with impending preterm birth. J Clin Endocrinol Metab., 83: $1585-1591$.

3. Iams J, Goldenberg R, Meis P et al. (1996): The length of the cervix and the risk of spontaneous premature delivery. National Institute of Child Health and Human Development Maternal Fetal Medicine Unit Network. N Engl J Med., 29: 567-572.

4. Berghella V, Palacio M, Ness A et al. (2017): Cervical length screening for prevention of preterm birth in singleton pregnancy with threatened preterm labor: Systematic review and meta-analysis of randomized controlled trials using individual patient-level data. Ultrasound Obstet Gynecol., 49: 322-329.

5. Guler A, Pehlivan H, Cakmak B et al. (2015): Assessment of fetal adrenal gland enlargement in term and preterm labor cases. Int J Res Med Sci., 3: 1035-1040.

6. Lindsay $J$, Nieman $L$ (2005): The hypothalamic-pituitaryadrenal axis in pregnancy: Challenges in disease detection and treatment. Endocr Rev., 26: 775-799.

7. Wadhwa P, Porto M, Garite T et al. (1998): Maternal corticotrophin releasing hormone levels in the early third trimester predict length of gestation in human pregnancy. Am J Obstet Gynecol., 179: 1079-1085.

8. Ochedalski T, Zylinska K, Laudanski T et al. (2001): Corticotrophin releasing hormone and ACTH levels in maternal and fetal blood during spontaneous and oxytocininduced labor. Eur J Endocrinol., 144: 117-121.

9. Agarwal A, Agarwal S (2017): Role of imaging and its advances in prediction of preterm birth. Int $\mathbf{J}$ Radiol Rad Ther., 2: 1-5.

10.Saito S, Nakashima A, Shima T, Ito M (2010): Th1/Th2/Th17 and regulatory T-cell paradigm in pregnancy. Am J Reprod Immunol., 63:601-10.

11. Hee L, Kirkegaard I, Vogel I et al. (2011): Low serum interlukin-17 is associated with preterm delivery. Acts Obstetricia et Gynecological Scandinavica, 90: 92-96.

12.Ito M, Nakashima A, Hidaka T et al. (2010): Role of IL17 in induction of an inflammation at the fetomaternal interface in preterm labor. Journal of Reproductive Immunology, (84): 75-85.

13. Carlson L, Feltovich H, Palmeri M et al. (2014): Estimation of shear wave speed in the human uterine cervix. Ultrasound Obste Gynecol., 43: 452-458.

14. Arias F, Daftary S, Bhide A (2011): Preterm labor. Practical guide to high-risk pregnancy and delivery. $3^{\text {rd }}$ ed. India: Elsevier, pp. 217-239.

15. Turan O, Turan S, Funai E et al. (2011): Ultrasound measurement of fetal adrenal gland enlargement: An accurate predictor of preterm birth. Am J Obstet Gynecol., 204-311.

16. Turan O, Turan S, Funai E et al. (2007): Fetal adrenal gland volume: A novel method to identify women at risk for impending preterm birth. Obstet Gynecol., 109: 855862.

17. Agarwal S, Agarwal A, Joon P et al. (2018): Fetal adrenal gland biometry and cervical elastography as predictors of preterm birth: A comparative study. Ultrasound, 26 (1): 5462.

18. Shobokshi A, Shaarawy M (2002): Maternal serum and amniotic fluid cytokine in patients with preterm premature rupture of membrane with and without intrauterine infection. International Journal of Gynecology and Obstetrics, 79: 209-215.

19. Gargano J, Holzman C, Senagore $P$ et al. (2008): Midpregnancy circulating cytokine levels, histologic chorioamnionitis and spontaneous preterm birth. J Reprod Immunol., 79(1):100-110. 